\title{
Kombinasi Kriptografi RSA dengan Linear Congruential Generator
}

\author{
Muhammad Khoiruddin Harahap \\ Teknik Informatika \\ Politeknik Ganesha Medan \\ Choir.harahap@yahoo.com
}

\author{
Rina \\ Teknik Informatika \\ Politeknik Ganesha Medan \\ qweenarynna@gmail.com
}

\begin{abstract}
Kriptografi menjadi sebuah teknik keamanan yang terus berkembang dan tak pernah selesai dalam pembahasannya. Keamanan terhadap data juga selalu menjadi perhatian yang sangat penting demi untuk menjaga kerahasiaan dan keamanan dari data tersebut. Dalam pembahasan ini bertujuan untuk menggabungkan dua buah algoritma yaitu pembangkit bilangan acak menggunakan metode Linear Congruential Generator untuk membuat tabel baru index bilangan ASCII yang kemudian dilanjutkan dengan Enkripsi / dekripsi menggunakan RSA. Melalui pembahasan tersebut didapatkanlah keamanan data menjadi 2 layer, yaitu layer pertama berdasarkan pengacakan code ASCII menjadi tabel baru dan Layer Kedua Enkripsi dan Dekripsi menggunakan metode RSA.
\end{abstract}

Keywords—LCG; RSA; Kriptografi; Sekuriti.

\section{PENDAHULUAN}

Keamanan data merupakan aspek yang sangat penting dalam pengiriman pesan terutama untuk pesan yang bersifat rahasia. Hal tersebut dapat kita lihat dari aktivitas sehari-hari seperti penggunaan internet untuk mengirimkan e-mail, sosial media, jual beli secara online, dan lain-lain. Untuk itu diperlukan suatu kode agar pesan tersebut masih bersifat rahasia dan aman, karena keamanan data yang dioperasionalkan pada jaringan publik rentan terhadap serangan oleh siapapun. Layanan keamanan data diwujudkan dengan menggunakan mekanisme keamanan data. Mekanisme keamanan data pada implementasinya menggunakan teknikteknik penyandian, yaitu kriptografi.

Penelitian oleh Martha Monica yang membahas tentang perbandingan dari berbagai algoritma kriptografi yang dapat dimanfaatkan dalam menjaga keamanan informasi dalam sebuah smart card. Terdapat 3 algoritma yang dibandingkan dalam penelitian ini, yaitu algoritma El Gamal, RSA, dan DES. Hasilnya algoritma RSA yang paling cocok digunakan pada sebuah smart card dibandingkan algoritma El Gamal dan DES. Walaupun tingkat keamanan pada RSA tidak setinggi algoritma El Gamal, namun masih lebih aman dibanding DES . Resource yang dibutuhkan juga tidak sebesar algoritma El Gamal sehingga algoritma RSA dapat menjadi pilihan yang tepat untuk penjagaan keamanan informasi yang tersimpan pada smart card(Monica 2013). I Made Divya Biantara, I Made Sudana, Alfa Faridh Suni, suryono dan Arimaz Hangga dari jurusan Teknik Electro Universitas Negeri Semarang membahas tentang penerapan pengacakan soal pada ujian komputerisasi yang bertujuan untuk memberikan soal acak yang berbeda kepada setiap siswa dengan menggunakan metode Linear Congruential (LCG) dan bantuan matrik yang menjadi Coupe Linear Congruential Generator (CLCG). Kelebihan dari sistem tersebut adalah Metode modifikasi CLCG menghasilkan pengacakan yang lebih baik dan pola yang lebih rumit dibandingkan dengan metode LCG.(Suni et al. 2015)

Penelitian ini menggunakan algoritma kriptografi Rivest, Shamir, Adleman (RSA) yang mengimplementasikan sistem kriptografi kunci publik dan dikombinasikan dengan algoritma pembangkit bilangan acak linear congruental generator (LCG), dalam hal ini menggunakan Big Prime Number (bilangan prima yang besar) untuk pengiriman pesan rahasia. Berdasarkan latar belakang diatas, maka penulis tertarik untuk melakukan penelitian dengan judul "Implementasi Penyandian Data Hibridisasi Rivest Shamir Adleman (RSA) Linear Congruental Generator (LCG) dan Mersenne Big Prime Number”. 


\section{Tinjauan Pustaka}

\subsection{Algoritma Kriptografi Asimetris}

Algoritma asimetris (asymmetric algorithm) adalah suatu algoritma dimana kunci enkripsi yang digunakan tidak sama dengan kunci dekripsi. Pada algoritma ini menggunakan dua kunci yaitu kunci publik (public key) dan kunci privat (private key). Disebut kunci publik karena kunci yang digunakan pada proses enkripsi dapat diketahui oleh orang banyak atau disebarkan secara umum. Sedangkan kunci privat yang digunakan untuk proses dekripsi disimpan secara rahasia oleh si pengguna. Mengetahui kunci publik semata tidak cukup untuk menentukan kunci rahasia. walau kunci publik telah diketahui namun akan sangat sukar mengetahui kunci privat yang digunakan. Dalam sistem kriptografi kunci publik ini, proses enkripsi dan dekripsi menggunakan kunci yang berbeda, namun kedua kunci tersebut memiliki hubungan matematis karena itu disebut juga sistem asimetris.

\subsection{Kriptografi Rivest Shamir Adleman (RSA)}

Dalam kriptografi, RSA adalah algoritma untuk enkripsi kunci publik (public-key encryption). RSA merupakan algoritma kriptografi yang paling sering digunakan karena sangat sulit untuk dipecahkan. RSA adalah singkatan dari huruf depan 3 orang yang menemukan algoritmanya, pada tahun 1977 di MIT (Massachussets Institute of Technology) yaitu Ron Rivest, Adi Shamir dan Len Adleman. Algoritma ini adalah kriptografi kunci simetri (kunci - publik) yang kuat sampai saat ini. (Stallings 1995) Pada tahun 1977, Rivest, Shamir, Adleman merumuskan algoritma praktis yang mengimplementasikan sistem kriptografi kunci publik disebut dengan sistem kriptografi RSA. RSA adalah salah satu teknik kriptografi dimana kunci untuk melakukan enkripsi berbeda dengan kunci untuk melakukan dekripsi. Kunci untuk melakukan enkripsi disebut sebagai kunci publik, sedangkan kunci untuk melakukan dekripsi disebut sebagai kunci privat. Orang yang mempunyai kunci publik dapat melakukan enkripsi tetapi yang dalam melakukan dekripsi hanya orang yang memiliki kunci privat. Kunci publik dapat dimiliki oleh sembarang orang, tetapi kunci privat hanya dimiliki oleh orang tertentu saja.

Algoritma enkripsi dan dekripsi sistem kriptografi RSA bersandar pada asumsi fungsi satu arah (one-way function) yang dibangun oleh fungsi eksponensial modular pada grup perkalian $\left(Z^{*} \mathrm{n}, \mathrm{x}\right)$ dan grup perkalian $\left(Z^{*} \varnothing(n), x\right)$ dengan

$\mathrm{n}=\mathrm{p} \times \mathrm{q}$. Dimana $\mathrm{p}, \mathrm{q}$ adalah bilangan prima $\operatorname{dan} \emptyset(\mathrm{n})=(\mathrm{p}-1)(\mathrm{q}-1)$.
Terdapat 3 algoritma pada sistem kriptografi RSA, yaitu algoritma pembangkitan kunci, algoritma enkripsi, dan algoritma dekripsi.

Untuk pembangkitan sepasang kunci RSA digunakan algoritma sebagai berikut :

1. Pilih dua bilangan prima yang besar, $p$ dan $q$

2. Hitung $\mathrm{n}=\mathrm{p}$. $\mathrm{q}$ nilai $\mathrm{n}$ tidak dirahasiakan

3. Hitung $\varnothing(n)=(p-1)(q-1)$

4. Pilih sebuah bilangan bulat sebagai kunci publik, sebut $e$. Dimana $e$ relatif prima terhadap $\varnothing(\mathrm{n})$, artinya faktor pembagi terbesar keduanya adalah 1. secara matematis disebut $\operatorname{gcd}(\mathrm{e}, \varnothing(\mathrm{n}))$ $=1$.

5. Hitung kunci privat, sebut d, dengan persamaan e.d $\equiv 1(\bmod \varnothing(n))$ atau $d \equiv$ e- $1 \bmod (\varnothing(n))$

Hasil dari algoritma diatas adalah : kunci publik adalah pasangan $(e, n)$ dan kunci privat adalah pasangan $(d, n)$.

\subsection{Algoritma Enkripsi dan Dekripsi RSA}

\section{a. Algoritma Enkripsi}

Untuk algoritma enkripsi menggunakan RSA adalah sebagai berikut :

1. Ambil kunci publik penerima pesan e dan modulus $n$.

2. Nyatakan pesan menjadi blok - blok plainteks $: \mathrm{m} 1, \mathrm{~m} 2, \mathrm{~m} 3, \ldots . .($ syarat $: 0<\mathrm{mi}<\mathrm{n}-1)$

3. Hitung blok cipherteks $\mathrm{C}$, dengan persamaan $\mathrm{Ci}=\mathrm{m}$. i. e $\bmod \mathrm{n}$. dalam hal ini e adalah kunci publik.

\section{b. Algoritma Dekripsi}

Untuk algoritma dekripsi menggunakan RSA adalah sebagai berikut :

Setiap blok cipherteks $\mathrm{Ci}$ didekripsi kembali menjadi blok mi dengan persamaan $\mathrm{mi}=\mathrm{c}$. i $\cdot \mathrm{d}$ mod $n$. dalam hal ini $d$ adalah kunci privat.

\subsection{Properti Algoritma RSA} RSA :

Besaran-besaran yang digunakan pada algoritma

- $\quad \mathrm{p}$ dan q bilangan prima (rahasia)

- $n=\mathrm{p} \cdot \mathrm{q} \quad$ (tidak rahasia)

- $\varnothing(n)=(\mathrm{p}-1)(\mathrm{q}-1) \quad($ rahasia $)$

- e (kunci enkripsi) (tidak rahasia)

- d (kunci dekripsi) (rahasia)

- m (plainteks) (rahasia)

- c (cipherteks) (tidak rahasia) 


\subsection{Linear Congruential Generator (LCG)}

Linear congruential generator merupakan algoritma pembangkit bilangan acak kongruen. Algoritma pseudo random number yang paling populer(Clawdia, Khairina, and Harahap 2017). Algoritma ini mudah dipahami dan dapat diimplementasikan secara cepat. Keuntungan dari LCG adalah operasinya yang sangat cepat. LCG dapat diterapkan untuk menghasilkan nilai acak atau digunakan untuk mengacak posisi dari sekumpulan nilai, dimana bilangan acak tersebut muncul berdasarkan rumus aritmatika yang sudah ditetapkan. LCG didefinisikan dalam relasi rekurens (Schneier 1996) dengan rumus :

$\mathrm{Z}_{\mathrm{i}}=\left(\mathrm{a} * \mathrm{Z}_{\mathrm{i}-1}+\mathrm{b}\right) \bmod \mathrm{m}$

Keterangan :

$\mathrm{Z}_{\mathrm{i}} \quad$ = bilangan acak ke $\mathrm{i}$ dari deretnya

$\mathrm{Z}_{\mathrm{i}-1}=$ bilangan acak sebelumnya

$\mathrm{a} \quad=$ faktor pengali

$\mathrm{b} \quad=$ penambah (increment)

$\mathrm{m}=$ modulus $(\mathrm{a}, \mathrm{b}$, dan $\mathrm{m}$ semuanya konstans)(Apdilah et al. 2018)

LCG mempunyai periode tidak lebih besar dari m, dan kebanyakan kasus periodenya kurang dari m, maksudnya adalah deret bilangan acak yang dihasilkan tidak lebih banyak dari modulonya. LCG mempuyai periode penuh $(\mathrm{m}-1)$ jika memenuhi syarat berikut (Munir 2006):

- $\quad b$ relative prima terhadap $m$

- a - 1 dapat dibagi dengan semua faktor prima dari $\mathrm{m}$

- a - 1 adalah kelipatan 4, jika m adalah kelipatan 4

- $\quad \mathrm{m}>\operatorname{maks}\left(\mathrm{a}, \mathrm{b}, \mathrm{X}_{0}\right)$

$-\quad a>0, b>0$

$\mathrm{X}_{0}$ adalah kunci pembangkit atau disebut juga umpan (seed). secara teori LCG mampu menghasilkan bilangan acak, namun sensitif terhadap pemilihan nilai-nilai $a, b$, dan $m$. Pemilihan nilai-nilai yang tidak sesuai dapat mempengaruhi implementasi pada LCG. LCG memiliki kelebihan pada kecepatannya karena sedikit membutuhkan operasi bit. namun kemunculan bilangan acaknya mudah diprediksi sehingga tidak aman secara kriptografi, namun demikian LCG tetap berguna untuk latihan awal penerapan enkripsi dengan metode stream cipher menggunakan kunci yang dibangkitkan oleh algoritma LCG.

\section{Pembahasan}

Langkah yang dilakukan pada pembahasan ini adalah yang pertama dilakukan yaitu membentuk sebuah bilangan urutan bilangan acak yang dikombinasi dengan membentuk deret yang acak dari ASCII code sebanyak 256 huruf. Dengan menggunakan CLG maka dibentuklah deret yang baru seperti tabel berikut ini dengan nilai nilai $\mathrm{a}=$ $1, \mathrm{~b}=7, \mathrm{~m}=256$ dan $\mathrm{Z}_{0}=12$.

\begin{tabular}{|c|c|c|c|c|c|c|c|}
\hline Index & asc index & Char & $\mathrm{z1}$ & Index & asc & Char & $\mathrm{z1}$ \\
\hline 1 & 0 & \#value! & 19 & 69 & 68 & D & 239 \\
\hline 2 & 1 & & 26 & 70 & 69 & $E$ & 246 \\
\hline 3 & 2 & & 33 & 71 & 70 & $\mathrm{~F}$ & 253 \\
\hline 4 & 3 & & 40 & 72 & 71 & $G$ & 4 \\
\hline 5 & 4 & & 47 & 73 & 72 & $\mathrm{H}$ & 11 \\
\hline 6 & 5 & & 54 & 74 & 73 & 1 & 18 \\
\hline 7 & 6 & & 61 & 75 & 74 & $\mathrm{~J}$ & 25 \\
\hline 8 & 7 & & 68 & 76 & 75 & $\mathrm{~K}$ & 32 \\
\hline 9 & 8 & & 75 & 77 & 76 & $\mathrm{~L}$ & 39 \\
\hline 10 & 9 & & 82 & 78 & 77 & $M$ & 46 \\
\hline 11 & 10 & & 89 & 79 & 78 & $\mathrm{~N}$ & 53 \\
\hline 12 & 11 & & 96 & 80 & 79 & 0 & 60 \\
\hline 13 & 12 & & 103 & 81 & 80 & $\mathrm{P}$ & 67 \\
\hline 14 & 13 & & 110 & 82 & 81 & $\mathrm{Q}$ & 74 \\
\hline 15 & 14 & & 117 & 83 & 82 & $R$ & 81 \\
\hline 16 & 15 & & 124 & 84 & 83 & $S$ & 88 \\
\hline 17 & 16 & & 131 & 85 & 84 & $\mathrm{~T}$ & 95 \\
\hline 18 & 17 & & 138 & 86 & 85 & $\mathrm{U}$ & 102 \\
\hline 19 & 18 & & 145 & 87 & 86 & $\mathrm{~V}$ & 109 \\
\hline 20 & 19 & & 152 & 88 & 87 & $w$ & 116 \\
\hline 21 & 20 & & 159 & 89 & 88 & $x$ & 123 \\
\hline 22 & 21 & & 166 & 90 & 89 & $\mathrm{Y}$ & 130 \\
\hline 23 & 22 & & 173 & 91 & 90 & Z & 137 \\
\hline 24 & 23 & & 180 & 92 & 91 & [ & 144 \\
\hline 25 & 24 & & 187 & 93 & 92 & 1 & 151 \\
\hline 26 & 25 & & 194 & 94 & 93 & ] & 158 \\
\hline 27 & 26 & & 201 & 95 & 94 & $\wedge$ & 165 \\
\hline 28 & 27 & & 208 & 96 & 95 & - & 172 \\
\hline 29 & 28 & & 215 & 97 & 96 & $\bar{v}$ & 179 \\
\hline 30 & 29 & & 222 & 98 & 97 & $A$ & 186 \\
\hline 31 & 30 & - & 229 & 99 & 98 & B & 193 \\
\hline 32 & 31 & & 236 & 100 & 99 & C & 200 \\
\hline 33 & 32 & & 243 & 101 & 100 & D & 207 \\
\hline 34 & 33 & $!$ & 250 & 102 & 101 & $E$ & 214 \\
\hline 35 & 34 & $"$ & 1 & 103 & 102 & $F$ & 221 \\
\hline 36 & 35 & $\#$ & 8 & 104 & 103 & $\mathrm{G}$ & 228 \\
\hline 37 & 36 & $\$$ & 15 & 105 & 104 & $\mathrm{H}$ & 235 \\
\hline 38 & 37 & $\%$ & 22 & 106 & 105 & 1 & 242 \\
\hline 39 & 38 & $\&$ & 29 & 107 & 106 & $\mathrm{~J}$ & 249 \\
\hline 40 & 39 & 1 & 36 & 108 & 107 & $\mathrm{~K}$ & 0 \\
\hline 41 & 40 & 1 & 43 & 109 & 108 & $\mathrm{~L}$ & 7 \\
\hline 42 & 41 & 1 & 50 & 110 & 109 & $M$ & 14 \\
\hline 43 & 42 & $*$ & 57 & 111 & 110 & $\mathrm{~N}$ & 21 \\
\hline 44 & 43 & + & 64 & 112 & 111 & 0 & 28 \\
\hline 45 & 44 & , & 71 & 113 & 112 & $P$ & 35 \\
\hline 46 & 45 & - & 78 & 114 & 113 & $Q$ & 42 \\
\hline 47 & 46 &. & 85 & 115 & 114 & $R$ & 49 \\
\hline 48 & 47 & 1 & 92 & 116 & 115 & $\mathrm{~S}$ & 56 \\
\hline 49 & 48 & 0 & 99 & 117 & 116 & $T$ & 63 \\
\hline 50 & 49 & 1 & 106 & 118 & 117 & $U$ & 70 \\
\hline 51 & 50 & 2 & 113 & 119 & 118 & $\mathrm{~V}$ & 77 \\
\hline 52 & 51 & 3 & 120 & 120 & 119 & W & 84 \\
\hline 53 & 52 & 4 & 127 & 121 & 120 & $x$ & 91 \\
\hline 54 & 53 & 5 & 134 & 122 & 121 & $\mathrm{Y}$ & 98 \\
\hline 55 & 54 & 6 & 141 & 123 & 122 & Z & 105 \\
\hline 56 & 55 & 7 & 148 & 124 & 123 & \{ & 112 \\
\hline 57 & 56 & 8 & 155 & 125 & 124 & 1 & 119 \\
\hline 58 & 57 & 9 & 162 & 126 & 125 & \} & 126 \\
\hline 59 & 58 & $:$ & 169 & 127 & 126 & $\sim$ & 133 \\
\hline 60 & 59 & ; & 176 & 128 & 127 & $\square$ & 140 \\
\hline 61 & 60 & $<$ & 183 & 129 & 128 & $€$ & 147 \\
\hline 62 & 61 & $=$ & 190 & 130 & 129 & - & 154 \\
\hline 63 & 62 & $>$ & 197 & 131 & 130 & , & 161 \\
\hline 64 & 63 & ? & 204 & 132 & 131 & $\mathrm{~F}$ & 168 \\
\hline
\end{tabular}




\begin{tabular}{|c|c|c|c|c|c|c|c|}
\hline 65 & 64 & @ & 211 & 133 & 132 & & 175 \\
\hline 66 & 65 & $A$ & 218 & 134 & 133 & $\ldots$ & 182 \\
\hline 67 & 66 & B & 225 & 135 & 134 & + & 189 \\
\hline 68 & 67 & $C$ & 232 & 136 & 135 & $\ddagger$ & 196 \\
\hline 137 & 136 & A & 203 & 214 & 213 & õ & 230 \\
\hline 138 & 137 & $\%$ & 210 & 215 & 214 & Ö & 237 \\
\hline 139 & 138 & S̆ & 217 & 216 & 215 & $x$ & 244 \\
\hline 140 & 139 & , & 224 & 217 & 216 & $\varnothing$ & 251 \\
\hline 141 & 140 & $\widetilde{\Phi E}$ & 231 & 218 & 217 & Ù & 2 \\
\hline 142 & 141 & $\bullet$ & 238 & 219 & 218 & ú & 9 \\
\hline 143 & 142 & Ž & 245 & 220 & 219 & $\hat{U}$ & 16 \\
\hline 144 & 143 & $\bullet$ & 252 & 221 & 220 & ü & 23 \\
\hline 145 & 144 & $\bullet$ & 3 & 222 & 221 & $\dot{Y}$ & 30 \\
\hline 146 & 145 & 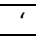 & 10 & 223 & 222 & $\mathrm{p}$ & 37 \\
\hline 147 & 146 & 1 & 17 & 224 & 223 & $B$ & 44 \\
\hline 148 & 147 & “ & 24 & 225 & 224 & $\grave{A}$ & 51 \\
\hline 149 & 148 & $"$ & 31 & 226 & 225 & $\dot{A}$ & 58 \\
\hline 150 & 149 & $\bullet$ & 38 & 227 & 226 & $\hat{A}$ & 65 \\
\hline 151 & 150 & - & 45 & 228 & 227 & $\tilde{A}$ & 72 \\
\hline 152 & 151 & - & 52 & 229 & 228 & $\ddot{A}$ & 79 \\
\hline 153 & 152 & $\sim$ & 59 & 230 & 229 & $\AA$ & 86 \\
\hline 154 & 153 & $\overline{T M}$ & 66 & 231 & 230 & $A E$ & 93 \\
\hline 155 & 154 & Š & 73 & 232 & 231 & Ç & 100 \\
\hline 156 & 155 & , & 80 & 233 & 232 & $\dot{\mathrm{E}}$ & 107 \\
\hline 157 & 156 & $\widetilde{C E}$ & 87 & 234 & 233 & É & 114 \\
\hline 158 & 157 & $\bullet$ & 94 & 235 & 234 & $\hat{\mathrm{E}}$ & 121 \\
\hline 159 & 158 & Ž & 101 & 236 & 235 & $\ddot{E}$ & 128 \\
\hline 160 & 159 & $\ddot{\gamma}$ & 108 & 237 & 236 & $\bar{\imath}$ & 135 \\
\hline 161 & 160 & & 115 & 238 & 237 & í & 142 \\
\hline 162 & 161 & $i$ & 122 & 239 & 238 & $\hat{\imath}$ & 149 \\
\hline 163 & 162 & $c$ & 129 & 240 & 239 & $\overline{\mathrm{i}}$ & 156 \\
\hline 164 & 163 & $f$ & 136 & 241 & 240 & $D$ & 163 \\
\hline 165 & 164 & $\not a$ & 143 & 242 & 241 & $\tilde{\mathrm{N}}$ & 170 \\
\hline 166 & 165 & $¥$ & 150 & 243 & 242 & ò & 177 \\
\hline 167 & 166 & 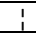 & 157 & 244 & 243 & ó & 184 \\
\hline 168 & 167 & $\S$ & 164 & 245 & 244 & ô & 191 \\
\hline 169 & 168 & & 171 & 246 & 245 & Õ & 198 \\
\hline 170 & 169 & (c) & 178 & 247 & 246 & Ö & 205 \\
\hline 171 & 170 & $\underline{a}$ & 185 & 248 & 247 & $\div$ & 212 \\
\hline 172 & 171 & " & 192 & 249 & 248 & $\varnothing$ & 219 \\
\hline 173 & 172 & 7 & 199 & 250 & 249 & Ù & 226 \\
\hline 174 & 173 & & 206 & 251 & 250 & Ú & 233 \\
\hline 175 & 174 & 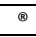 & 213 & 252 & 251 & $\hat{U}$ & 240 \\
\hline 176 & 175 & - & 220 & 253 & 252 & Ü & 247 \\
\hline 177 & 176 & $\circ$ & 227 & 254 & 253 & $\dot{Y}$ & 254 \\
\hline 178 & 177 & \pm & 234 & 255 & 254 & p & 5 \\
\hline 179 & 178 & 2 & 241 & 256 & 255 & $\ddot{\gamma}$ & 12 \\
\hline 180 & 179 & 3 & 248 & & & & \\
\hline 181 & 180 & ' & 255 & & & & \\
\hline 182 & 181 & $\mu$ & 6 & & & & \\
\hline 183 & 182 & 9 & 13 & & & & \\
\hline 184 & 183 & $\cdot$ & 20 & & & & \\
\hline 185 & 184 & & 27 & & & & \\
\hline 186 & 185 & 1 & 34 & & & & \\
\hline 187 & 186 & $\underline{0}$ & 41 & & & & \\
\hline 188 & 187 & $"$ & 48 & & & & \\
\hline 189 & 188 & $1 / 4$ & 55 & & & & \\
\hline 190 & 189 & $1 / 2$ & 62 & & & & \\
\hline 191 & 190 & $3 / 4$ & 69 & & & & \\
\hline 192 & 191 & $i$ & 76 & & & & \\
\hline 193 & 192 & $\grave{A}$ & 83 & & & & \\
\hline 194 & 193 & $\bar{A}$ & 90 & & & & \\
\hline 195 & 194 & $\hat{A}$ & 97 & & & & \\
\hline 196 & 195 & $\tilde{A}$ & 104 & & & & \\
\hline 197 & 196 & $\ddot{A}$ & 111 & & & & \\
\hline 198 & 197 & $\AA$ & 118 & & & & \\
\hline 199 & 198 & $A E$ & 125 & & & & \\
\hline 200 & 199 & Ç & 132 & & & & \\
\hline 201 & 200 & $\grave{\mathrm{E}}$ & 139 & & & & \\
\hline 202 & 201 & $\bar{E}$ & 146 & & & & \\
\hline 203 & 202 & $\hat{\mathrm{E}}$ & 153 & & & & \\
\hline 204 & 203 & $\ddot{\mathrm{E}}$ & 160 & & & & \\
\hline 205 & 204 & ̀̀ & 167 & & & & \\
\hline 206 & 205 & Í & 114 & & & & \\
\hline
\end{tabular}

\begin{tabular}{|c|c|c|c|}
\hline 207 & 206 & $\hat{\imath}$ & 181 \\
\hline 208 & 207 & ï & 188 \\
\hline 209 & 208 & $\theta$ & 195 \\
\hline 210 & 209 & $\tilde{\mathbf{N}}$ & 202 \\
\hline 211 & 210 & Ò & 209 \\
\hline 212 & 211 & Ó & 216 \\
\hline 213 & 212 & Ô & 223 \\
\hline
\end{tabular}

Berdasarkan tabel di atas, maka didapatkanlah index yang baru untuk urutan ascii sebagai berikut :

\begin{tabular}{|c|c|c|c|c|c|c|c|c|c|}
\hline CHR & INDX & CHR & INDX & CHR & INDX & CHR & INDX & CHR & INDX \\
\hline $\mathrm{K}$ & 0 & & 68 & $f$ & 136 & 7 & 148 & ó & 216 \\
\hline " & 1 & $3 / 4$ & 69 & $z$ & 137 & $\hat{\imath}$ & 149 & Š & 217 \\
\hline Ù & 2 & $U$ & 70 & & 138 & $¥$ & 150 & A & 218 \\
\hline$\bullet$ & 3 & , & 71 & $\grave{\mathrm{E}}$ & 139 & 1 & 151 & $\varnothing$ & 219 \\
\hline G & 4 & $\tilde{A}$ & 72 & $\square$ & 140 & & 152 & - & 220 \\
\hline $\mathrm{P}$ & 5 & Š & 73 & 6 & 141 & $\hat{\mathrm{E}}$ & 153 & $\mathrm{~F}$ & 221 \\
\hline$\mu$ & 6 & $Q$ & 74 & í & 142 & $\bullet$ & 154 & & 222 \\
\hline $\mathrm{L}$ & 7 & & 75 & $\not x$ & 143 & 8 & 155 & ô & 223 \\
\hline$\#$ & 8 & $\bar{i}$ & 76 & {[} & 144 & $\ddot{i}$ & 156 & 1 & 224 \\
\hline ú & 9 & V & 77 & & 145 & $i$ & 157 & B & 225 \\
\hline 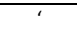 & 10 & - & 78 & É & 146 & ] & 158 & Ù & 226 \\
\hline $\mathrm{H}$ & 11 & $\ddot{A}$ & 79 & $€$ & 147 & & 159 & $\circ$ & 227 \\
\hline$\ddot{Y}$ & 12 & , & 80 & 7 & 148 & $\ddot{\mathrm{E}}$ & 160 & G & 228 \\
\hline ก & 13 & $R$ & 81 & $\hat{\imath}$ & 149 & , & 161 & - & 229 \\
\hline$M$ & 14 & & 82 & $¥ ¥$ & 150 & 9 & 162 & Õ & 230 \\
\hline$\$$ & 15 & $\grave{A}$ & 83 & 1 & 151 & $\theta$ & 163 & $\overline{G E}$ & 231 \\
\hline$\hat{U}$ & 16 & W & 84 & & 152 & $\S$ & 164 & C & 232 \\
\hline , & 17 & . & 85 & $\hat{E}$ & 153 & $\wedge$ & 165 & Ú & 233 \\
\hline 1 & 18 & $\AA$ & 86 & $\bullet$ & 154 & & 166 & \pm & 234 \\
\hline \#value! & 19 & CE & 87 & 8 & 155 & ì & 167 & $\mathrm{H}$ & 235 \\
\hline$\cdot$ & 20 & $\mathrm{~S}$ & 88 & $\ddot{i}$ & 156 & $\mathrm{~F}$ & 168 & & 236 \\
\hline $\mathrm{N}$ & 21 & & 89 & $i$ & 157 & : & 169 & Ö & 237 \\
\hline$\%$ & 22 & $\bar{A}$ & 90 & ] & 158 & $\tilde{N}$ & 170 & $\bullet$ & 238 \\
\hline Ü & 23 & $x$ & 91 & & 159 & $"$ & 171 & $\mathrm{D}$ & 239 \\
\hline " & 24 & 1 & 92 & Ë & 160 & - & 172 & $\hat{U}$ & 240 \\
\hline \multirow[t]{2}{*}{$\mathrm{J}$} & 25 & $A E$ & 93 & , & 161 & & 173 & 2 & 241 \\
\hline & 26 & $\bullet$ & 94 & 9 & 162 & Í & 174 & $\mathrm{I}$ & 242 \\
\hline . & 27 & $T$ & 95 & D & 163 & $"$ & 175 & & 243 \\
\hline 0 & 28 & & 96 & $\S$ & 164 & ; & 176 & $x$ & 244 \\
\hline$\&$ & 29 & $\hat{A}$ & 97 & $\Lambda$ & 165 & ò & 177 & Ž & 245 \\
\hline$\dot{Y}$ & 30 & $Y$ & 98 & & 166 & (c) & 178 & $E$ & 246 \\
\hline$"$ & 31 & 0 & 99 & $\bar{i}$ & 167 & & 179 & Ü & 247 \\
\hline \multirow[t]{2}{*}{$\mathrm{K}$} & 32 & Ç & 100 & $\mathrm{~F}$ & 168 & & 180 & 3 & 248 \\
\hline & 33 & Ž & 101 & $:$ & 169 & $\hat{\imath}$ & 181 & J & 249 \\
\hline 1 & 34 & U & 102 & $\tilde{\mathbf{N}}$ & 170 & $\ldots$ & 182 & $!$ & 250 \\
\hline$P$ & 35 & & 103 & $"$ & 171 & $<$ & 183 & $\varnothing$ & 251 \\
\hline ' & 36 & $\tilde{A}$ & 104 & - & 172 & Ó & 184 & • & 252 \\
\hline $\mathrm{P}$ & 37 & $z$ & 105 & & 173 & $\underline{a}$ & 185 & $\mathrm{~F}$ & 253 \\
\hline$\bullet$ & 38 & 1 & 106 & í & 174 & $A$ & 186 & $\hat{Y}$ & 254 \\
\hline \multirow[t]{2}{*}{$\mathrm{L}$} & 39 & È & 107 & $"$ & 175 & & 187 & & 255 \\
\hline & 40 & $\ddot{\gamma}$ & 108 & ; & 176 & $\ddot{i}$ & 188 & & \\
\hline 음 & 41 & V & 109 & ò & 177 & + & 189 & & \\
\hline$Q$ & 42 & & 110 & (c) & 178 & $=$ & 190 & & \\
\hline 1 & 43 & $\ddot{A}$ & 111 & 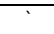 & 179 & Ô & 191 & & \\
\hline$B$ & 44 & \{ & 112 & & 180 & $"$ & 192 & & \\
\hline- & 45 & 2 & 113 & $\hat{\imath}$ & 181 & B & 193 & & \\
\hline \multirow[t]{2}{*}{$M$} & 46 & $\bar{E}$ & 114 & $\ldots$ & 182 & & 194 & & \\
\hline & 47 & & 115 & $<$ & 183 & $\theta$ & 195 & & \\
\hline$"$ & 48 & W & 116 & Ó & 184 & $\ddagger$ & 196 & & \\
\hline$R$ & 49 & & 117 & $\underline{a}$ & 185 & $>$ & 197 & & \\
\hline 1 & 50 & $\AA$ & 118 & $A$ & 186 & Õ & 198 & & \\
\hline $\bar{A}$ & 51 & 1 & 119 & & 187 & ᄀ & 199 & & \\
\hline- & 52 & 3 & 120 & $i ̈$ & 188 & C & 200 & & \\
\hline \multirow[t]{2}{*}{$\mathrm{N}$} & 53 & $\hat{\mathrm{E}}$ & 121 & + & 189 & & 201 & & \\
\hline & 54 & $i$ & 122 & $=$ & 190 & $\tilde{N}$ & 202 & & \\
\hline $1 / 4$ & 55 & $x$ & 123 & Ô & 191 & $n$ & 203 & & \\
\hline $\mathrm{s}$ & 56 & & 124 & $f$ & 136 & $?$ & 204 & & \\
\hline
\end{tabular}




\begin{tabular}{|c|c|c|c|c|c|c|c|}
\hline * & 57 & $A E$ & 125 & Z & 137 & Ö & 205 \\
\hline Á & 58 & \} & 126 & & 138 & & 206 \\
\hline$\sim$ & 59 & 4 & 127 & 衣 & 139 & $\mathrm{D}$ & 207 \\
\hline 0 & 60 & 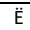 & 128 & $\square$ & 140 & & 208 \\
\hline & 61 & $c$ & 129 & 6 & 141 & ò & 209 \\
\hline $1 / 2$ & 62 & $Y$ & 130 & Í & 142 & $\%$ & 210 \\
\hline$T$ & 63 & & 131 & $\not$ & 143 & @ & 211 \\
\hline+ & 64 & Ç & 132 & [ & 144 & $\div$ & 212 \\
\hline$\hat{\mathrm{A}}$ & 65 & $\sim$ & 133 & & 145 & 7 & 213 \\
\hline$T M$ & 66 & 5 & 134 & É & 146 & $\mathrm{E}$ & 214 \\
\hline$P$ & 67 & $\grave{\imath}$ & 135 & $€$ & 147 & & 215 \\
\hline
\end{tabular}

Berdasarkan tabel yang baru terbentuk maka dilakukanlah proses enkripsi dan dekripsi menggunakan original RSA dan contoh dapat dilihat sebagai berikut :

Sebagai contoh dalam mengimplementasikan diatas adalah sebagai berikut :

\section{Plaintext : RIN}

Plaintext di LCG menghasilkan : , š , - dengan ascii code masing masing $=81,18,53$

Hasil Enkripsi :

Ambil nilai $\mathrm{p}=11$ dan $\mathrm{q}=19$, maka didapatkanlah Enkripsi $=16,94,70$

Dan pada proses dekripsi akan mengembalikan ke nilai Dekripsi $=81,18,53$

\section{KESIMPULAN}

Berdasarkan pembahasan di atas, maka dapat ditarik kesimpulan bahwa penggabungan LCG dengan RSA dapat membuat sekuritas dari data menjadi 2 layer, dimana layer pertama bahwa plaintext terlebih dahulu diacak kemudian dilanjutkan hasil acak tersebut di lakukan proses Enkripsi, dan juga sebaliknya, hasil enkripsi di dekripsi untuk kemudian di lakukan proses LCG lagi untuk mengembalikan ke plaintext semua.

\section{REFERENCES}

Apdilah, D., M.K. Harahap, N. Khairina, A.M. Husein, and M. Harahap. 2018. "A Comparison of One Time Pad Random Key Generation Using Linear Congruential Generator and Quadratic Congruential Generator." Journal of Physics: Conference Series 1007 (1). https://doi.org/10.1088/17426596/1007/1/012006.
Clawdia, Jhessica, Nurul Khairina, and Muhammad Khoiruddin Harahap. 2017. "Implementasi Algoritma Kriptografi One Time Pad (Otp) Dengan Dynamic Key Linear Congruential Generator (Lcg).” KOMIK (Konferensi Nasional Teknologi Informasi Dan Komputer) I: 12-14.

Monica, Martha. 2013. "Pemanfaatan Algoritma Kriptografi Dalam Pembuatan Smart Card." Makalah IF3058 Kriptografi-Semester II Tahun 2012/2013, no. 13510080.

Munir, Rinaldi. 2006. Kriptografi.

Schneier, Bruce. 1996. Applied Cryptography, Second Edition: Protocols, Algorthms, and Source Code in C (Cloth).

Stallings, William. 1995. Cryptography and Network Security (4th Edition).

Suni, Alfa Faridh, Arimaz Hangga, I Made Sudana, and I Made Diyya Biyantara. 2015. "Modifikasi Metode Linear Congruential Generator." SemNaSIF 2015 (November): 182-86. 